\title{
ALHAJJ - HAJJ APP FOR IOS
}

\author{
Adnan ShaOUT AND SHAHZEb KHAN \\ The Electrical \& Computer Engineering Department, \\ The University of Michigan - Dearborn, \\ Dearborn, Michigan 48128, USA. \\ shaout@umich.edu,andshahzeb@umich.edu \\ (Received: 05 Nov. 2014; Accepted: 28 Sept. 2015; Published on-line: 30 Apr. 2016)
}

\begin{abstract}
This paper introduces the AlHajj app for iOS which is an interactive guide to Hajj, like an interactive map allowing users to walk through the process of the Hajj to develop a better understanding of the obligations, locations, dates and Hajj activities with the sequence they are performed in. It covers both pre and post Hajj activities. AlHajj has a very simplistic and clean User Interface (UI). The app is also written for maintainability and it is free.
\end{abstract}

ABSTRAK: Kertas kerja ini memperkenalkan aplikasi AlHajj untuk iOS yang merupakan panduan interaktif bagi ibadah Haji saperti peta interaktif yang menjelaskan pada pengguna mengenai aktiviti-aktiviti dalam mengerjakan Haji dan ia memberi penjelasan yang mendalam mengenai tanggungjawab, lokasi, tarikh dan aktiviti haji mengikut urutan mereka dilakukan . Applikasi ini meliputi aktiviti sebelum dan selepas haji. AlHajj mempunyai antaramuka pengguna yang sangat mudah dan ringkas (UI). Aplikasi ini mudah dislenggarakan dan ia adalah percuma.

KEYWORDS: Hajj; iOS; Software Tools; Interactive Map; Mobile App; Islam

\section{INTRODUCTION}

About three to four million Muslims travel to Mecca every year to perform one of the five pillars of Islam: Hajj (pilgrimage). Hajj involves a series of obligations/rituals that have to be fulfilled/performed over the course of five to six days. It also involves traveling between various sacred locations [1]. Most pilgrims attend training sessions, or go over other material to prepare them for Hajj.

There exist many works done on helping pilgrims during their holy trip to Mecca [216]. In today's mobile world, more people have started to use smart-phones to consume information. Therefore usage of mobile apps and mobile websites for information consumption has increased. Some mobile apps pertaining to the obligations of Hajj already exist on the App Store, but we did not find them as interactive, informative and as organized as we would have liked. Some of the apps that were tried were too dull, while some were purely based on linear scrolling through all the steps of Hajj.

The idea of AlHajj is to have a more interactive guide to Hajj, allowing users to walk through the process of the Hajj to develop a better understanding of the obligations, locations, dates and the order in which these rituals are performed. Another feature, such as pre-Hajj customizable checklist can also be beneficial to pilgrims, which is not found in most of the existing Hajj apps.

This paper is organized such that it begins with discussing the state of the art and differentiators for AlHajj in section 2. The feature list of AlHajj is covered in section 3. 
Then it discusses the technologies used in the application in section 4. Section 5 sheds some light on the software tools used and implementation details as well as an appendix on how to recreate the AlHajj App for iOS. Also appendix B has the implementation Code for the AlHajj App.The possible future enhancements are discussed in section 6. The paper ends with a conclusion about AlHajj in section 7.

\section{STATE OF THE ART}

Currently a few applications exist in the App Store that aim at helping people with their Hajj journey.

One such app is Hajj Guide [17]. This is a very basic application. It is based completely on static text and images. It has hard to read text due to the font size and the amount of static text on the screen. There is no interactivity whatsoever.

Another similar app is Complete Hajj Guide [18]. It too suffers from some of the same problems as the Hajj Guide App. It doesn't have any interactive elements either. Also, this app costs $\$ 0.99$ as opposed to AlHajj, which is free.

Hajj \& Umrah [19] is another app that tries to solve the same problem. However, it has the same problems as already discussed for the application above. The information is not very well organized either. There are too many menus to dig through, which makes a user feel that the information could perhaps be more streamlined. On top of all that, this app costs $\$ 1.99$ as well.

Hajj \& Umrah Easy Steps [20] too is a paid app with all static content, currently priced at $\$ 0.99$. This app has a poor user interface with color combinations so bad that it will take some effort to read information being presented to the user. Also, this app, like the aforementioned apps, does not have any interactive elements.

\subsection{AlHajj Differentiators (Unique Features)}

\subsubsection{Interactivity}

AlHajj is all about interactivity. Interactivity starts from the pre-hajj preparation checklist to the rituals that are required for Hajj. AlHajj makes users take actions and responds accordingly. This keeps the users in the mode of continues learning and excited. None of the previously mentioned apps exhibit this level of interactivity.

\subsubsection{Pre and Post Hajj Coverage}

AlHajj is a complete package. It starts with the material required to ensure that a person is absolutely ready to depart for the journey of Hajj, and it also includes motivational messages from the Quran and Hadeeth to ensure that pilgrims stay motivated and on the right path even after they are done with Hajj.

\subsubsection{Clean UI}

AlHajj has a very simplistic and clean User Interface (UI). The font sizes, arrangement and organization of the text, makes it easily readable. Also, only two colors have been used throughout the app: black and white. This helps ensure that users are focused on the actual material and are not distracted by anything flashy.

\subsubsection{Free}

- AlHajj costs nothing as compared to the other related apps in the market. Despite the fact that AlHajj has more to offer, it is free. 


\subsubsection{Maintainability}

The ability to easily edit the content in the AlHajj app is a huge plus. All the static content of the app is organized in separate plist and text files, which makes it easy to update any piece of static content. This too gives AlHajj an edge over other competitors.

\section{ALHAJJ FEATURE LIST}

The major features of AlHajj are:

a) Interactive Checklist

b) Interactive Hajj Map

c) Interactive Contact List

d) Motivational Messages (Chirps)

A brief description of each of these features is as follows:

\subsection{Interactive Checklist}

This is a checklist of items that need to be accomplished before departing on the journey for Hajj. These items are mostly question like "Have you paid all your debts?" or "Have you written your will?" The users are able to utilize a set of default checklist items. The user can also add more items to the list to suit their needs or to fulfill the requirements specific by their country of origin. They can mark items as done and delete the ones that do not apply to them. Figure 1 shows screenshots of the interactive checklist.
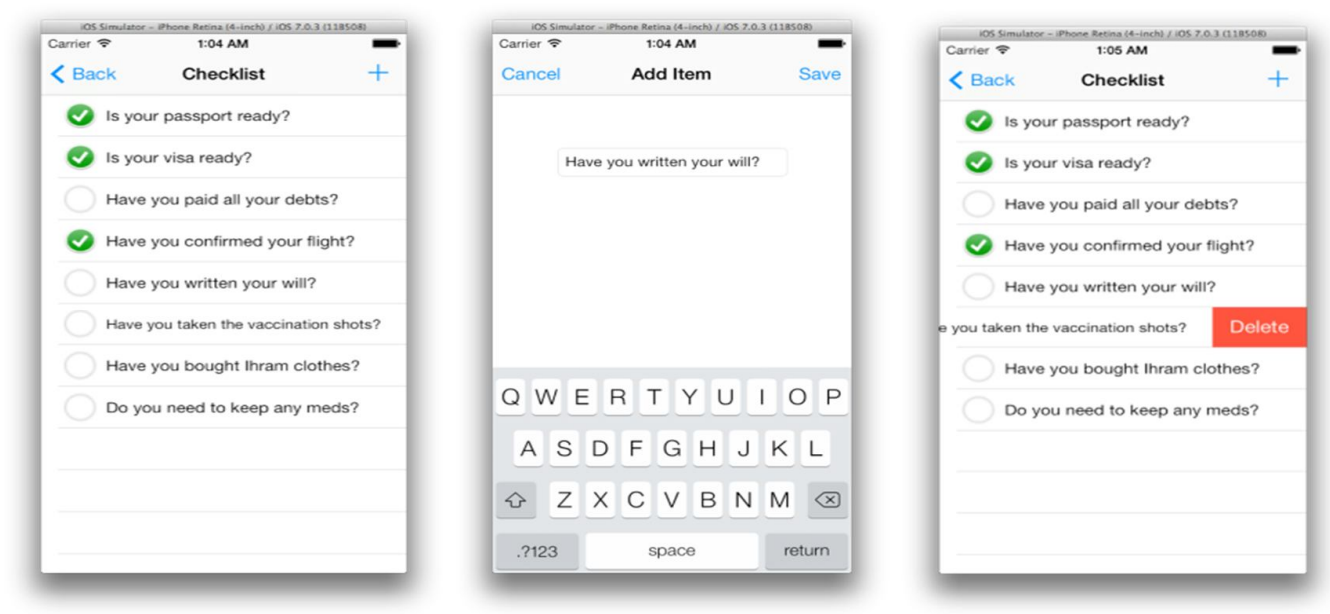

Fig. 1: Screenshots of the interactive checklist.

\subsection{Interactive Hajj Map}

AlHajj lets users learn about the procedures of Hajj through an interactive map that they can walkthrough. The map lets users see what needs to be done, at what date and at what location. It allows users to go through each location that needs to be visited in the correct order. It also allows the user togo back to previous locations to see what they have already done.

While at a location they can tap the location, or the "See Details" button to view all the details of procedures that need to be performed at that location. Once users have finished walking through the entire process, the map asks them if they want to start over. Users can 
always reset the map by clicking the "Reset Map" button, even when in the middle of the walkthrough and start over. Figure 2 shows the interactive map screenshots.
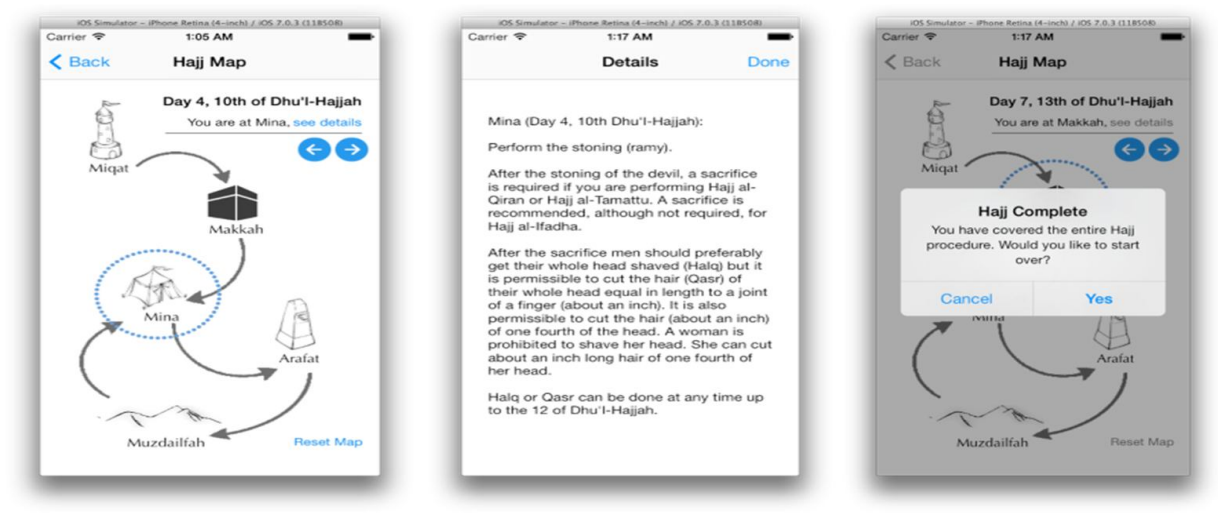

Fig. 2: Interactive Map Screenshots.

\subsection{Interactive Contact List}

This is a list of all of the important contacts that the users may need during their stay in Saudi Arabia for Hajj. The set of default contacts include Saudi Police Department, Fire Department, Highway Patrol, Ambulance, etc. Users can add more contacts to this list as well to suit their personal needs and requirements. However, users are only allowed to delete contacts that they have themselves added, and not the default ones.

Another great ability related to the interactive contacts list, is the ability to dial a phone number from within AlHajj. The user doesn't need to exit the app to dial a number. All the user has to do is to tap the number that he/she wants to dial in the AlHajj contact list. The app will then ask for confirmation, and the number will be dialed. This is a great convenience, and will definitely come in handy if an emergency situation is encountered. Figure 3 shows the Interactive Contact List Screenshots.
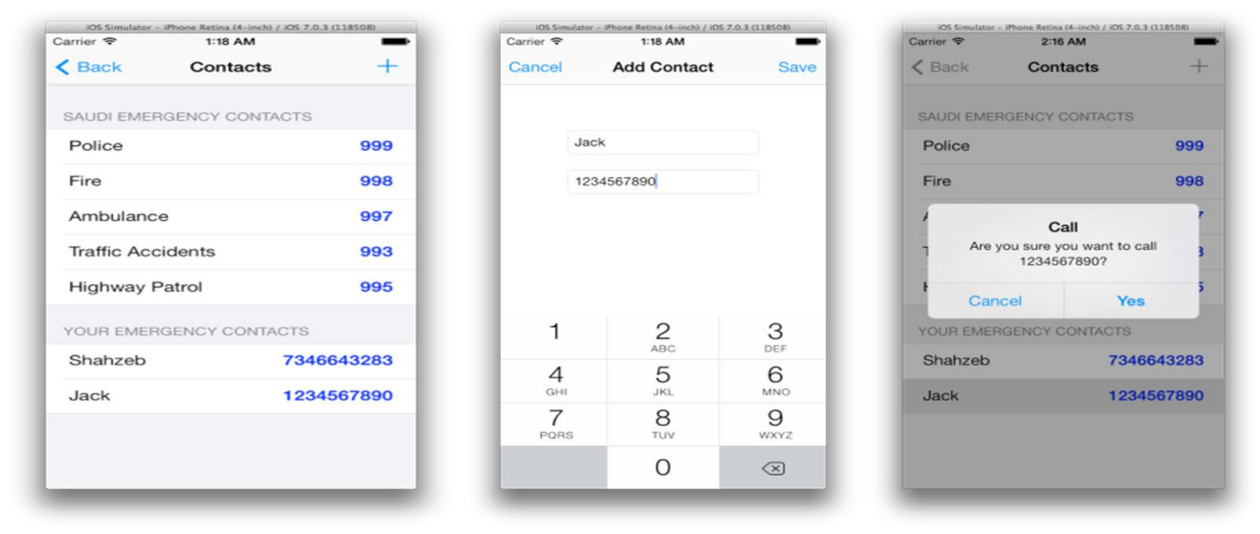

Fig. 3: Interactive Contact List Screenshots.

\subsection{Motivational Messages (Chirp)}

AlHajj allows users to setup a time to receive motivational messages on their phone. These messages can be Quranic quotations, a Hadeeth or anything else, aimed at boosting the religious spirit of the users. There are three hundred and sixty six slots for these 
messages. Each slot corresponds to a day of the year. Hence, users will receive a different motivational message each day. Users can always go back and change the time they want to receive these messages. They can also completely turn off these messages if they want. Figure 4 shows motivational messages screenshots.
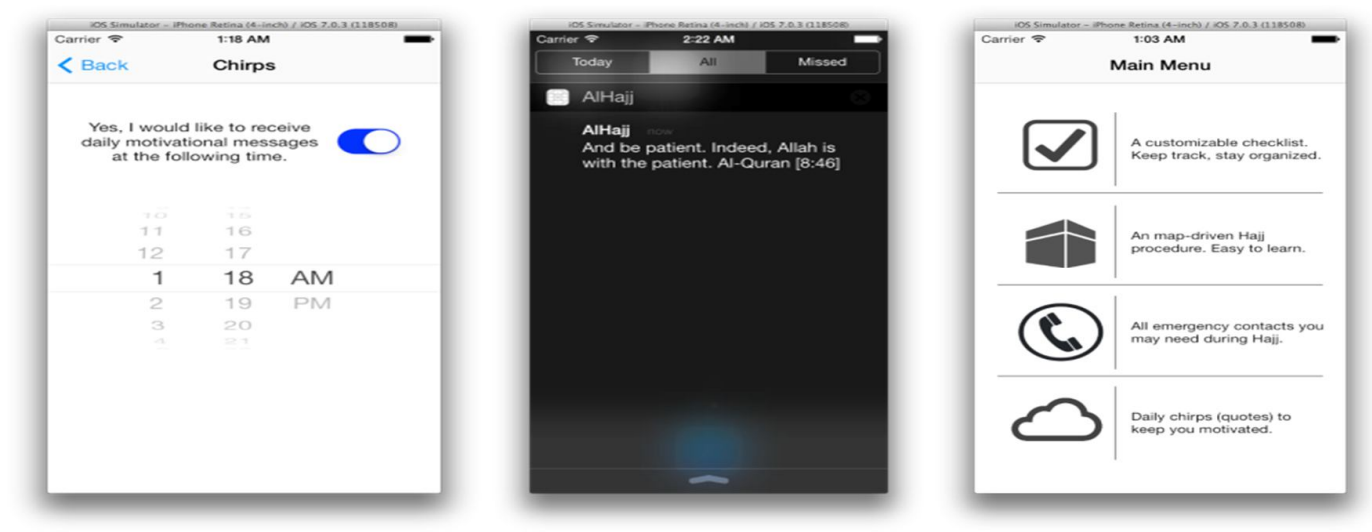

Fig. 4: Motivational messages screenshots.

\section{SOFTWARE TOOLS USED}

\section{1 iOS SDK, Objective C, Xcode}

This is the most important and core package of tools that was needed for this app. Applications for iOS cannot be developed without using the iOS SDK [21], which is based on Objective-C [22]. Xcode [23] is Apple's integrated development environment for developing apps for mobile (iOS) and desktop (OS X) devices.

\subsection{Bitbucket / GitX}

As the codebase for this paper started to grow, it was impossible to keep track of the changes manually. Therefore we hosted the code in a repository on Bitbucket [24]. It is free, which allows version control using mercurial and git.

GitX [25] was also used locally. It is a client for Mac, which helps in keeping track of all the changes on the local and remote branches of code.

\section{IMPLEMENTATION DETAILS}

\subsection{Interactive Checklist}

To implement the checklist, the UI for the checklist view is implemented using the storyboard. The view is sub-classed from the UITableView class to get all the necessary attributes of the native iOS table view. Each row of the table is an item of the checklist.Prototype cells have been used to customize each row of the cell. Each prototype cell has an image view embedded inside it towards the leftand a text view adjacent to it. The image view is used to show and hide the green checkmark, which signifies the completion of a task. The text view is used to display the actual text for the checklist item.

Table view delegate methods have been implemented to capture the behavior of tapping a table row, which turns the checkmark on or off.Also, the swiping left on a table row will bring up an option to delete it. Corresponding delegate methods have been implemented to handle deletion. 
All the items present in the list by default are populated by using a plist file present in the code base. Items can be added or removed from it to alter the default list of items.

In order to add new items to this list, a separate add view is implemented. It is subclassed from UIView, instead of UITableView, since this is a simple view and not a table view. The UI is implemented using the storyboard. Anything saved here is added to the original list.

\subsection{Interactive Hajj Map}

To implement the interactive Hajj map, the UI for the map view has been laid out by using the storyboard. The view is sub-classed off of a UIView. All the image views are positioned in the storyboard. These image viewshave been used for all locations and for circles around them, like Mecca, Mina, etc. Images have also been used for all arrows, representing traveling between the various locations. Text views are used to represent all the text on the map view. The next/previous, see details and reset map buttons are implemented using iOS native UIButton.

When the view is initialized all arrows are kept hidden, all locations are visible and only onecircle is displayed, which is on the initial location (Miqat).The entire sequence of traveling is loaded into arrays. For example, all arrows are ordered into an array, and all labels for each location are ordered into an array as well. When the next button is tapped, logic is triggered to move to the next element in the various arrays. Similarly, tapping previous button triggers logic to go to the previous element in the various arrays. This affects what is shown and what is hidden, and thus forms the interactive map.

In order to view procedure details for a particular location, a separate detail view has been implemented. It is sub-classed from UIView. There are about nine location points that require reading details. However, implementing nine separate views to handle this would have been pretty tough to maintain. Therefore, only one detail view has been implemented with nine text files containing the details. The detail view dynamically loads one of these nine files, based on the current location of the user.

\subsection{Interactive Contact List}

To implement the contact list, the UI for the contact list view is implemented using the storyboard. The view is sub-classed from the UITableView class to get all the necessary attributes of the native iOS table view. Each row of the table is an item of the contact list. Prototype cells have been used to customize each row of the cell. Each prototype cell has two text views. The text view on the left is used for the name of the contact, and text view on the right is used to display the phone number for the corresponding contact.

The table view is divided into two sections to accommodate the two kinds of contacts: default contacts and user contacts. The default contacts are stored in a static plist file that is part of the code base. This file can be edited to alter the default contact list. Users are also able to add their own contacts to this list. These contacts appear in a separate section on the table view and can be deleted.

In order to add new items to this list, a separate add view is implemented. It is subclassed from UIView, instead of UITableView, since this is a simple view and not a table view. The UI is implemented using the storyboard. Anything saved here is added to the original list.

Table view delegate methods have been implemented to capture the behavior of tapping a table row, which triggers a UIAlertView asking if the user wants to make a phone call to the tapped contact. If the user taps "Yes", a phone call is made from with the AlHajj app. 


\subsection{Motivational Messages}

To implement the motivational messages, the UI for the chirps view has been laid out by using the storyboard. The view is sub-classed off of a UIView. UIDatePicker has been used for date selection, and a UISwitch has been used to turn these motivational messages on or off. All of these motivational messages are stored in a separate plist file that is part of the code base.

UILocalNotifications have been used for scheduling and triggering these messages. Sinceeach day is supposed to have its unique motivational message, it requires that three hundred and sixty six notifications be scheduled to trigger the messages every day of the year.

Apple does not allow more than 64 local notifications to be scheduled at a time by an application [26], which posed a serious problem. The solution around this was to schedule sixty notifications each time the app is launched. This schedules enough messages for the nextcouple of months, with a single launch of the app.

Appendix A has the recreation of the AlHajj App for iOS. Appendix B has the implementation Code for the AlHajj App.

\section{FUTURE ENHANCEMENTS}

\subsection{Geo-location}

One important feature that can be added to this app is the ability to track the location of fellow group/family members using GPS, since it is easy to get lost in a crowd of four million people.

\subsection{Audio for Arabic Du'as}

It will be useful to add audio for Arabic Du'as in the app, which will open another avenue of learning for the users.

\subsection{More Visual Elements}

More visual elements can be added to the app in the future, like simple images or animations, to graphically explain some of the procedures of Hajj.

\section{CONCLUSION}

AlHajj is an App that has a more interactive guide to Hajj, like an interactive map allowing users to walk through the process of the Hajj to develop a better understanding of the obligations, locations, dates and sequence they are performed in. The App also has a unique feature which is a pre-Hajj customizable checklist. This feature can be beneficial to pilgrims, which is not found in most of the existing Hajj apps. Hence, AlHajj is a clear winner when compared to the other related apps in the market today.

\section{REFERENCES}

[1] Hajj General Information [http://www.hajinformation.com/flashdaybyday.htm]

[2] Geabel A, Jastaniah K, Abu Hassan R, Aljehani R, Babadr M, Abulkhair M. (2014) Pilgrim Smart identification using RFID technology (PSI). Marcus A. (Ed.): DUXU 2014, Part III, LNCS 8519, Springer International Publishing, pp. 273-280. 
[3] Mohandes M, Haleem MA, Kousa M, Balakrishnan K. (2013) Pilgrim tracking and identification using wireless sensor networks and GPS in a mobile phone. Arab J Sci Eng, 38:2135-2141.

[4] Taileb M, Al-Ghamdi E, Al-Ghanmi N, Al-Mutari A, Al-Jadani K, Al-Ghamdi M, Al-Mutari A. (2014) Manasek AR: A location-based augmented reality application for Hajj and Umrah. Shumaker R and Lackey S. (Eds.): VAMR 2014, Part II, LNCS 8526, Springer International Publishing, pp. 134-143.

[5] Mitchell RO, Rashid H, Dawood F, AlKhalidi A. (2013) Hajj crowd management and navigation system people tracking and location based services via integrated mobile and RFID systems. IEEE conference 978-1-4673-5285-7/13.

[6] Ali MAT, Berri J, Zemerly MJ. (2008) Context aware mobile Muslim companion. CSTST October 27-31, 2008, Cergy-Pontoise, France.

[7] Hamhoum F, Kray C. (2012) Supporting pilgrims in navigating densely crowded religious sites. Pervasive Ubiquity Computers, 16:1013-1023.

[8] Muaremi A, Tr" oster G, Seiter J, Bexheti A. (2013) Monitor and understand pilgrims: Data collection using smart phones and wearable devices. UbiComp'13, September 8-12, 2013, Zurich, Switzerland.

[9] Zeki AM, Alsafi H, Nassr RM, Mantoro t. (2012) A mobile dictionary for pilgrims. The 2012 International Conference on Information Technology and e-Services.

[10] Mohandes MA. (2012) Near field communication for pilgrim services. The 8th International Conference on Computing Technology and Information Management (ICCM).

[11] Malak Osman and Adnan Shaout (2015), "Overview of Mobile Help for Performing Hajj Rituals", the International Journal of Emerging Technology \& Advanced Engineering (ISSN 2250-2459, ISO 9001:2008 Certified Journal), Volume 5, Issue 10, October 2015.

[12] Malak Osman and Adnan Shaout (2014), "Hajj Guide Systems - Past, Present and Future", the International Journal of Emerging Technology \& Advanced Engineering (ISSN 22502459, ISO 9001:2008 Certified Journal), Volume 4, Issue 8, August 2014.

[13] Ali Alao, Adnan Shaout, Malak Osman (2015), "Tawaf Counting”, the proceedings of the 3nd International Conference on Islamic Applications in Computer Science and Technology (IMAN 2015) 1-3 October 2015 Konya, Turkey.

[14] Malak Osman, Adnan Shaout and M. Mohandes (2015), "Easy Hajj Applications Track \& Educate Pilgrims", the proceedings of the 3nd International Conference on Islamic Applications in Computer Science and Technology (IMAN 2015) 1-3 October 2015 Konya, Turkey.

[15] Malak Osman and Adnan Shaout (2015), "Pilgrim Communication Using Mobile Phones", the proceedings of the ICCTS 2015, Bandar Seri Begawan, Brunei June 2015.

[16] Malak Osman and Adnan Shaout (2015), "Towards Developing an Intelligent Hajj Guide System - Pilgrim Tracking and Identification Using Mobile Phones", the proceedings of the 7th International Conference on Information Technology (ICIT2015), Amman, Jordan May 2015.

[17] Hajj Guide App by ImranQureshi.com, 2011 [https://itunes.apple.com/us/app/hajj-guide/id473635756]

[18] Complete Hajj Guide App by Cyber Designz, 2012 [https://itunes.apple.com/us/app/complete-haji-guide/id560955425]

[19] Hajj \& Umrah App by AMC Apps, 2013 [https://itunes.apple.com/us/app/hajj-umrah/id471282657?mt=8]

[20] Hajj \& Umrah Easy Steps App by Pearls Productions UK, 2011 [https://itunes.apple.com/app/id400656429]

[21] iOS SDK [https://developer.apple.com/technologies/ios/]

[22] Objective $\mathrm{C}$ [https://developer.apple.com/library/mac/documentation/cocoa/conceptual/ProgrammingWit hObjectiveC/Introduction/Introduction.html]

[23] Xcode [https://developer.apple.com/xcode/]

[24] Bitbucket [https://bitbucket.org/]

[25] GitX [http://gitx.frim.nl/] 
[26] iOS Local Notifications [https://developer.apple.com/library/ios/documentation/NetworkingInternet/Conceptual/Rem oteNotificationsPG/Chapters/WhatAreRemoteNotif.html] 


\section{Appendix A: Recreating AlHajj App for iOS}

Here are the steps for recreating AlHajj app for iOS.

1. Launch Xcode using Launchpad.

2. Click "Create a new Xcode project".

3. Select "Single View Application" Template as shown in Fig. a1.

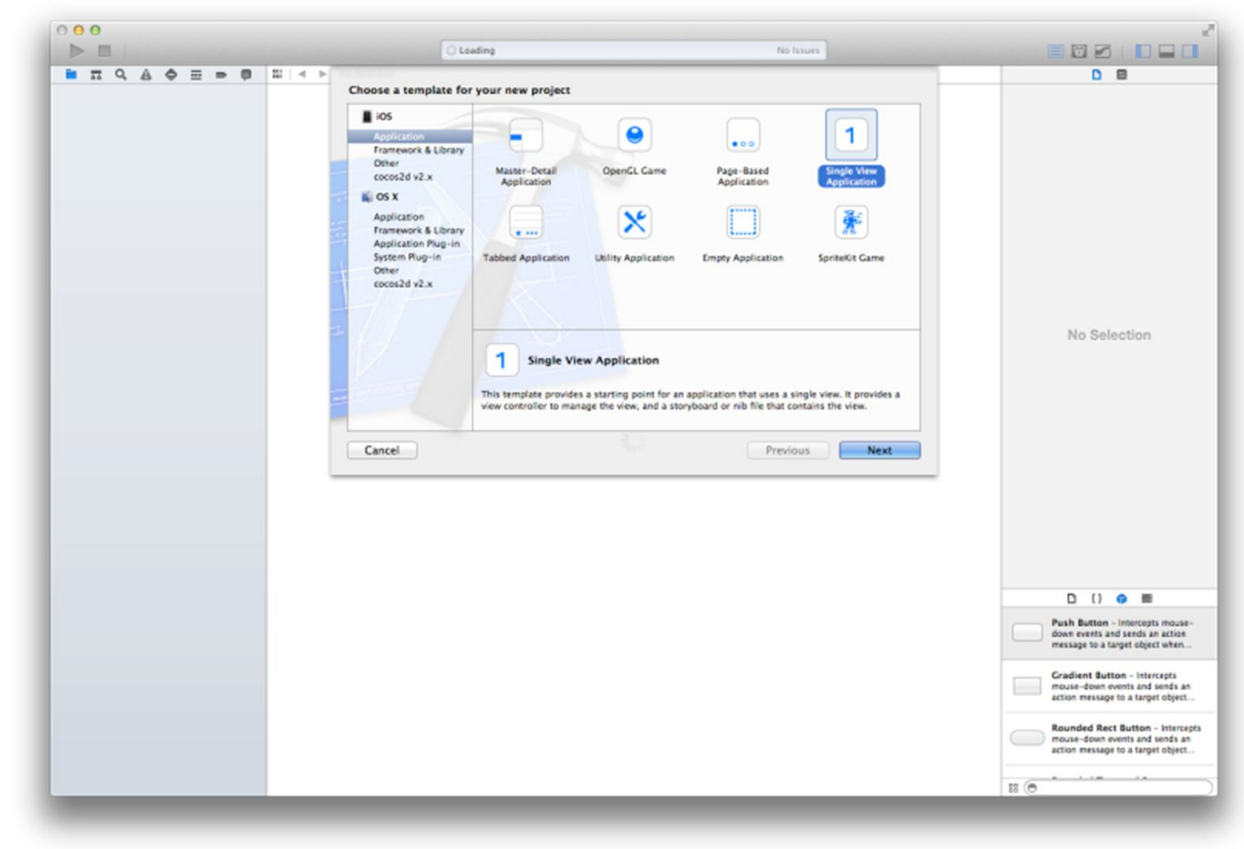

Fig. a1: Design template.

4. Click "Next".

5. Fill in the name of the app.

6. Select the destination folder for the project.

7. Click "Create" as shown in Fig. a2 and a3.
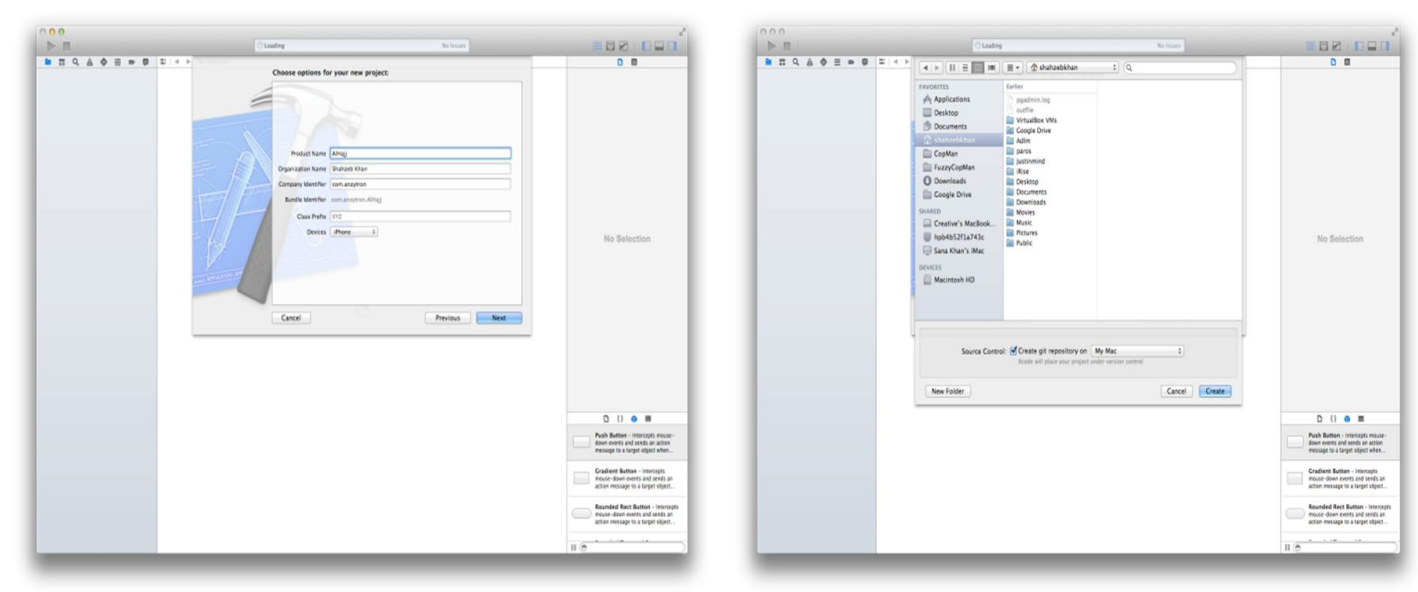

Fig. a2: Creating a project. 


\section{Checklist Development:}

1. Create a new plist file called Checklist.plist to hold default items, using the file menu shown in Fig. a3.

\begin{tabular}{|c|c|c|}
\hline Key & Type & Value \\
\hline Root & Array & (8 items) \\
\hline$\nabla$ Item 0 & Dictionary & (1 item) \\
\hline Is your passport ready? & Boolean & No \\
\hline VItem 1 & Dictionary & (1 item) \\
\hline Is your visa ready? & Boolean & No \\
\hline vitem 2 & Dictionary & (1 item) \\
\hline Have you paid all your debts? & Boolean & No \\
\hline vitem 3 & Dictionary & (1 item) \\
\hline Have you confirmed your flight? & Boolean & No \\
\hline Vitem 4 & Dictionary & (1 item) \\
\hline Have you written your will? & Boolean & No \\
\hline Vitem 5 & Dictionary & (1 item) \\
\hline Have you taken the vaccination shots? & Boolean & No \\
\hline VItem 6 & Dictionary & (1 item) \\
\hline Have you bought Ihram clothes? & Boolean & NO \\
\hline Vitem 7 & Dictionary & (1 item) \\
\hline Do you need to keep any meds? & Boolean & No \\
\hline
\end{tabular}

Fig. a3: The file menu for the check list.

2. Create a new checklist view as a table view of prototype cells using the storyboard as shown in Fig. a4.

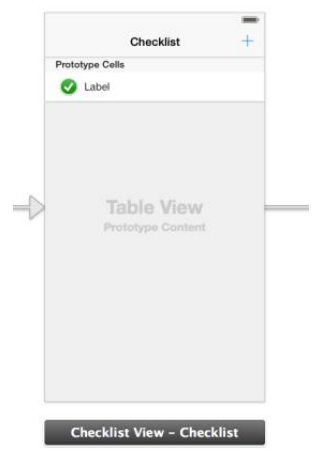

Fig. a4: Prototype cells.

3. Create a new add item view with a UITextfield and toolbar items, using the storyboard as shown in Fig. a5.

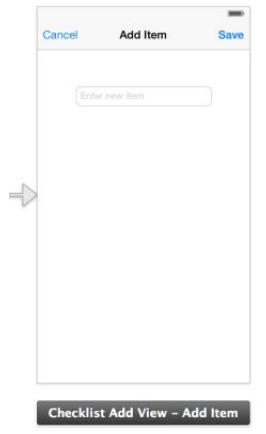

Fig. a5: An add item view.

4. Create a class to contain all code and logic for the checklist view.

5. Create a class to contain all code and logic for the checklist add view.

6. Connect all IBOutlets.

7. Implement view lifecycle methods (viewDidLoad, viewWillAppear, etc).

8. Implement table view delegate methods.

9. Implement methods to read from and write to the plist file.

10. Implement methods to pass data between the two views. 


\section{Hajj Map Development:}

1. Create text files to store Hajj procedure details, using the file menu.

2. Create a new map view using the storyboard as shown in Fig. a6.

3. Use UIImageViews for all arrows and locations, and UIButtons for circles.

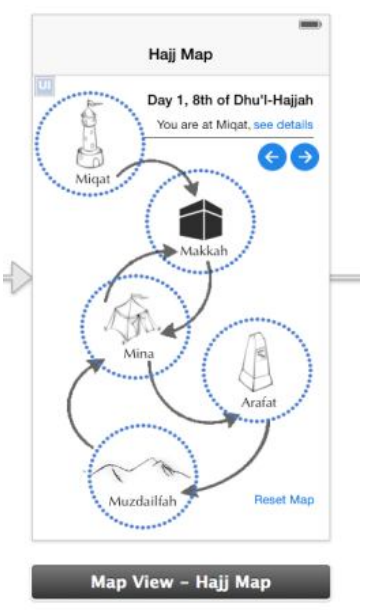

Fig. a6: A new map view using the storyboard.

4. Create a new detail view with a UITextView and toolbar items, using the storyboard as shown in Fig. a7.

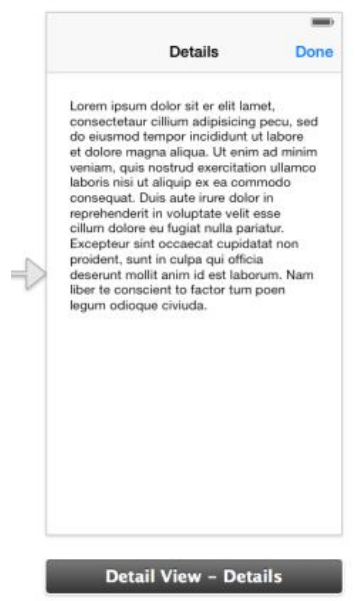

Fig. a7:Creating a new detail view.

5. Create a class to contain all code and logic for the map view.

6. Create a class to contain all code and logic for the detail view.

7. Connect all IBOutlets.

8. Implement logic to load all items into arrays.

9. Implement logic to traverse back and forth between items of these arrays.

10. Implement logic to show and hide items based on the selected item in an array.

11. Implement logic to dynamically load procedure details into the detail view. 


\section{Contact List Development:}

1. Create a plist file called Contacts.plist to store all default contacts, using the file menu as shown in Fig. a8.

\begin{tabular}{|c|c|c|}
\hline Key & Type & Value \\
\hline$\nabla$ Root & Array & (5 items) \\
\hline$\nabla$ Item 0 & Dictionary & (1 item) \\
\hline Police & String & 999 \\
\hline$\nabla$ Item 1 & Dictionary & (1 item) \\
\hline Fire & String & 998 \\
\hline$\nabla$ Item 2 & Dictionary & (1 item) \\
\hline Ambulance & String & 997 \\
\hline$\nabla$ Item 3 & Dictionary & (1 item) \\
\hline Traffic Accidents & String & 993 \\
\hline$\nabla$ Item 4 & Dictionary & (1 item) \\
\hline Highway Patrol & String & 995 \\
\hline
\end{tabular}

Fig. a8: The file menu for the contact list.

2. Create a new contacts view as a table view of prototype cells using the storyboard as shown in Fig. a9.

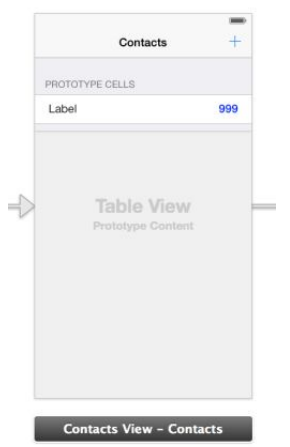

Fig. a9: Creating a new contacts view as a table view of prototype cells.

3. Create a new add item view with UITextFields and toolbar items, using the storyboard as shown in Fig. a10.

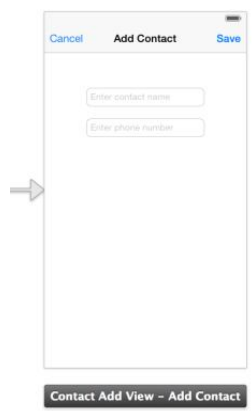

Fig. a10: Creating a new add item view.

4. Create a class to contain all code and logic for the contacts view.

5. Create a class to contain all code and logic for the contact add view.

6. Connect all IBOutlets.

7. Implement view lifecycle methods (viewDidLoad, viewWillAppear, etc).

8. Implement table view delegate methods.

9. Implement methods to read from and write to the plist file.

10. Implement methods to pass data between the two views.

11. Implement method to trigger a phone call when a row is tapped. 


\section{Motivational Messages Development:}

1. Create a plist file called Chirps.plist to store all default chirps, using the file menu as shown in Fig a11.

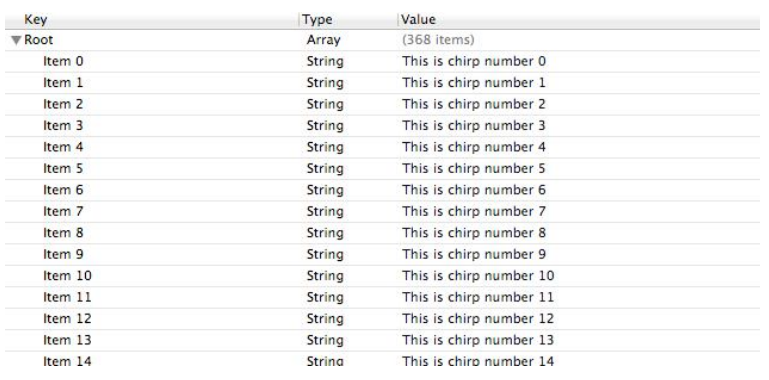

Fig. a11: Creating a plist file called Chirps.plist to store all default chirps.

2. Create a new chirp's view with a UIDatePicker and a UISwitch, using the storyboard as shown in Fig. a12.

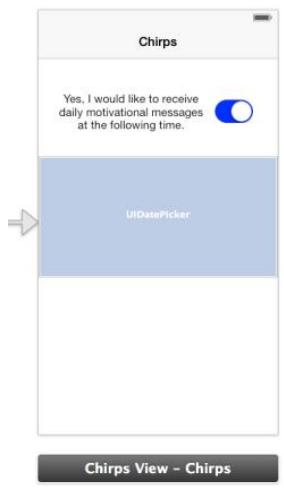

Fig. a12: Creating a new chirp's view with a UIDatePicker and a UISwitch.

3. Create a class to contain all code and logic for the chirps view.

4. Connect all IBOutlets.

5. Implement UIPickerView delegate methods.

6. Implement scheduling of notifications using UILocalNotification.

7. Implement logic to enable/disable notifications based on the UISwitch's state.

\section{Main Menu Development:}

1. Create a new main menu view with UIButtons and UILabels, using the storyboard as shown in Fig. a13.

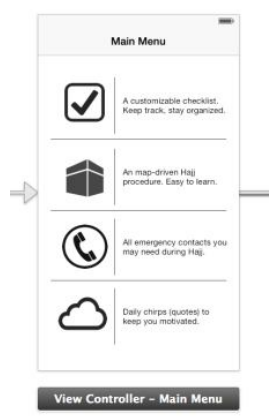

Fig. a13: Creating a new main menu view with UIButtons and UILabels.

2. Use Control + Drag to connect each button to the respective view. 


\section{Navigation Development:}

1. Control + Drag from the source UI element to destination view element to trigger navigation from a UI element to a view.

2. Once you leave the mouse click on the destination you will presented with various options. Pick "modal" if you are connecting a detail view to a parent view (e.g. Contacts view to contact adds view). Pick "push" for regular navigation between screens.

3. Once you are done setting up all navigation, your storyboard should like Fig. a14.

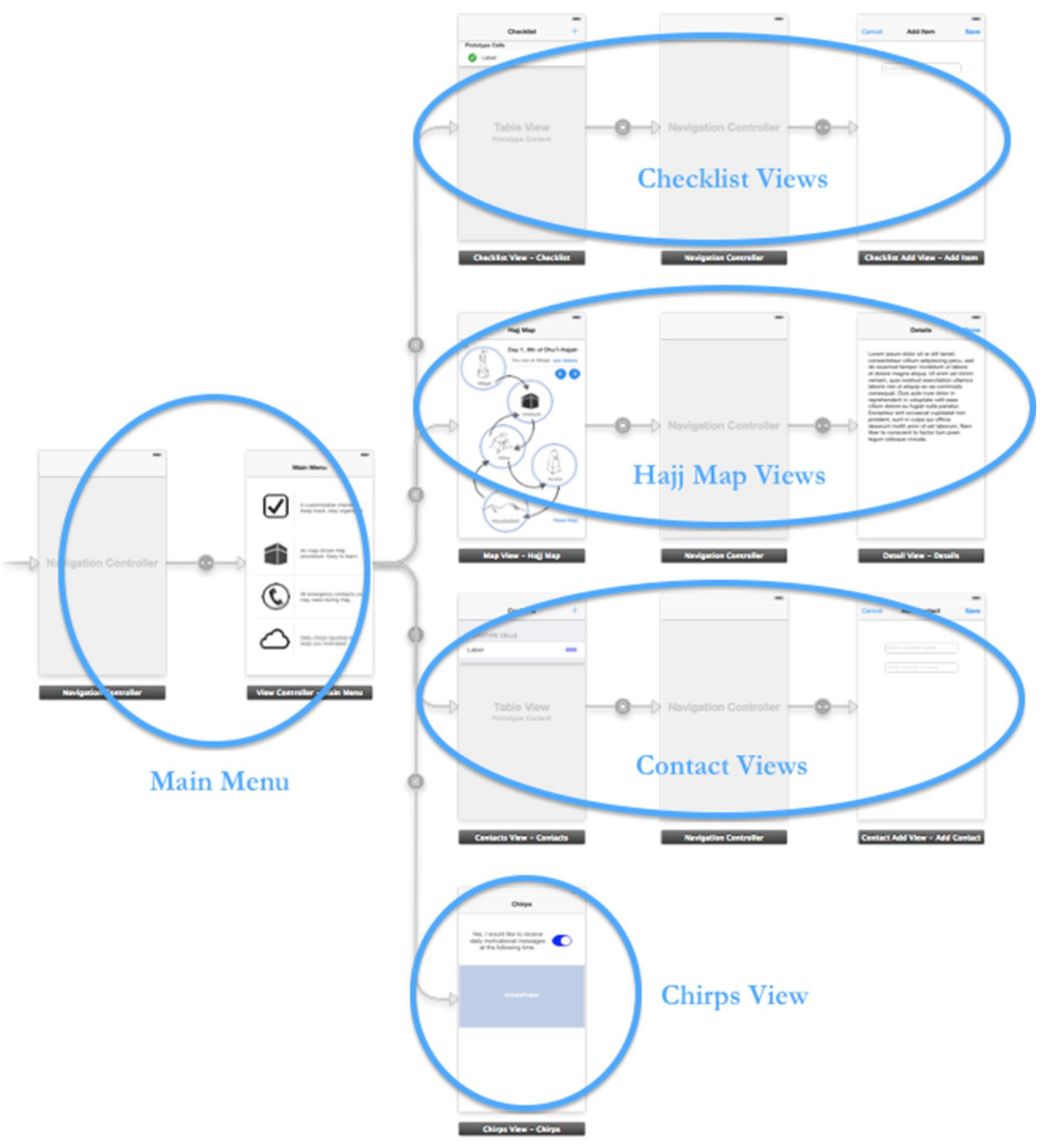

Fig. a14: Storyboard. 


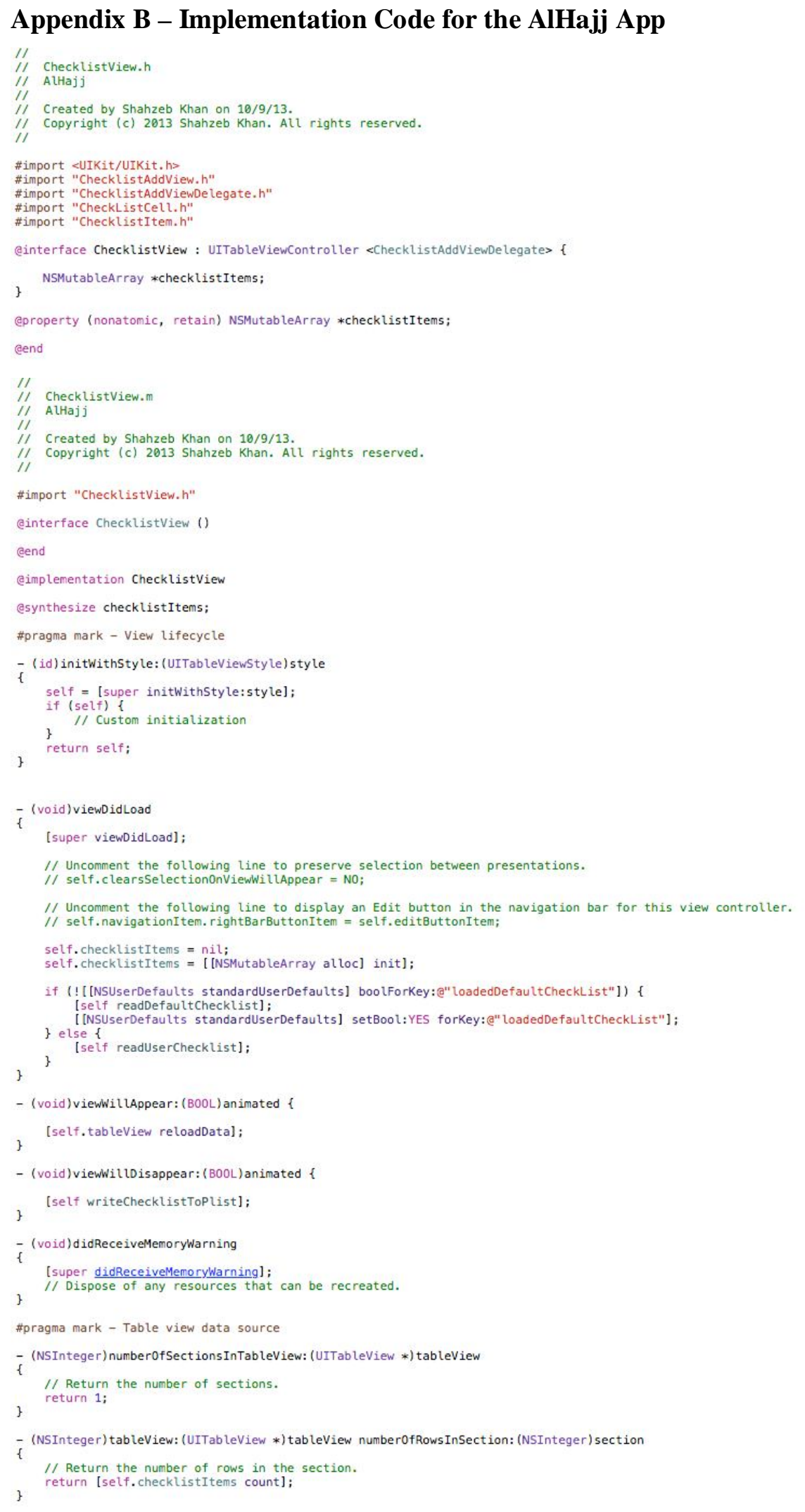




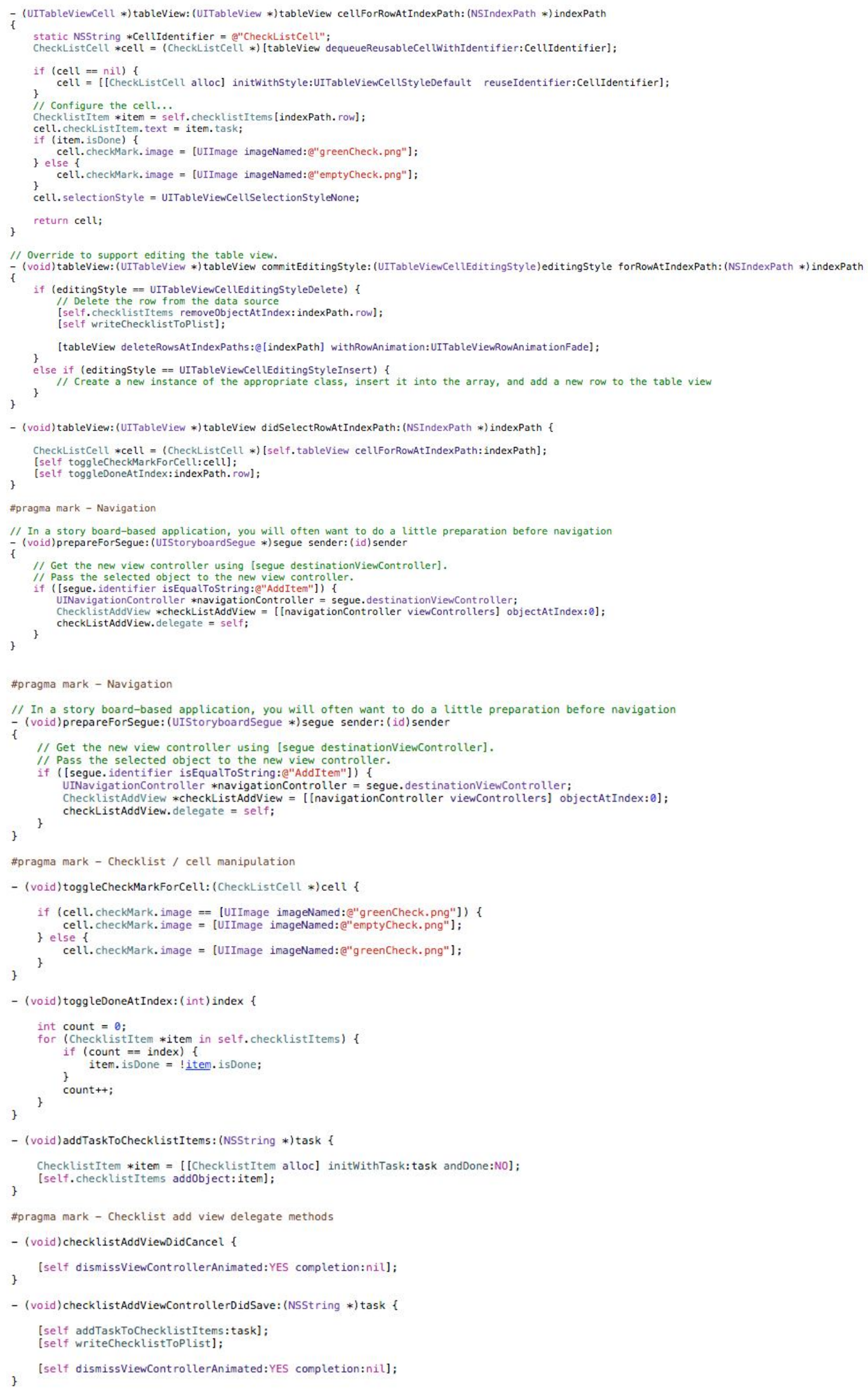




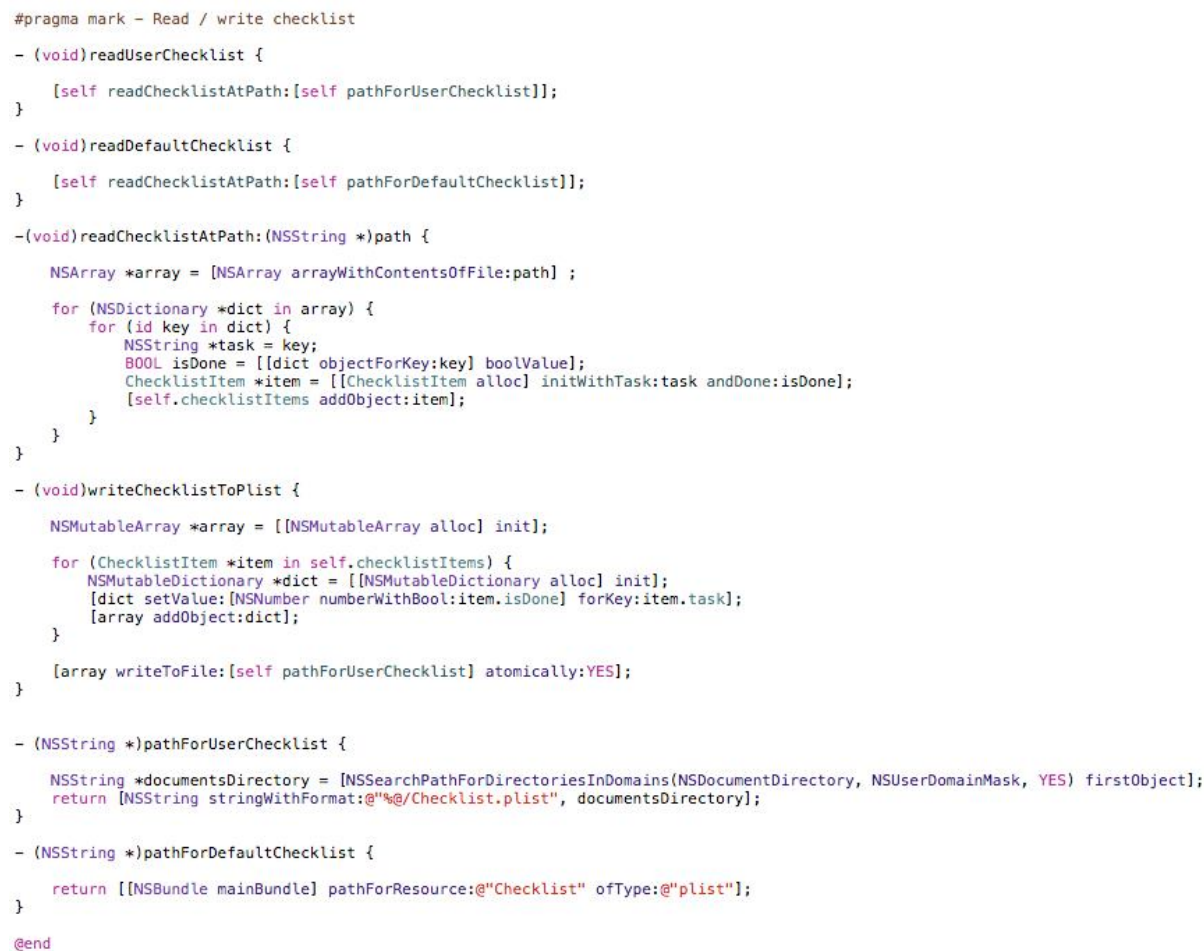

Fig. b1: Interactive Checklist Code. 


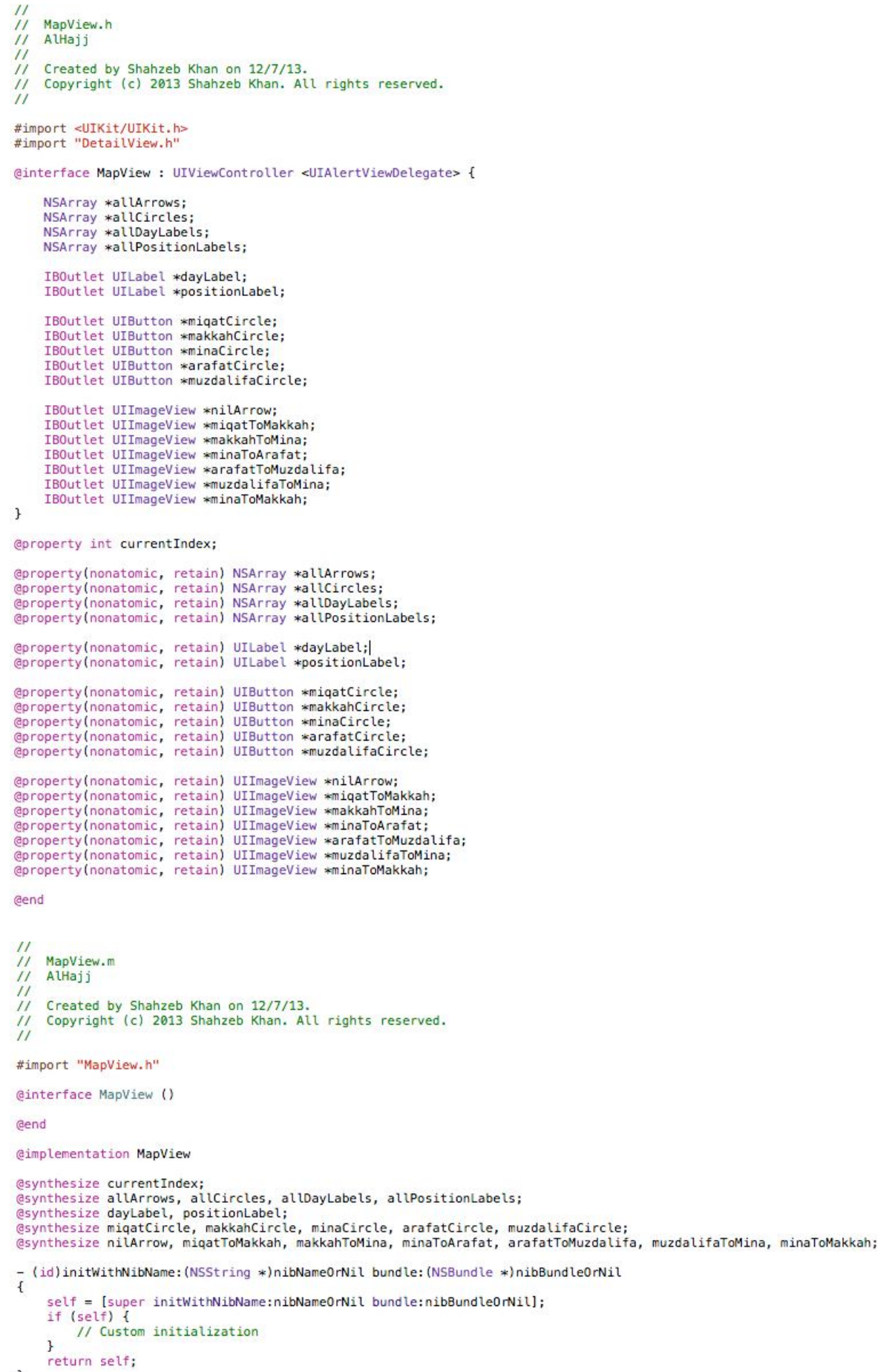




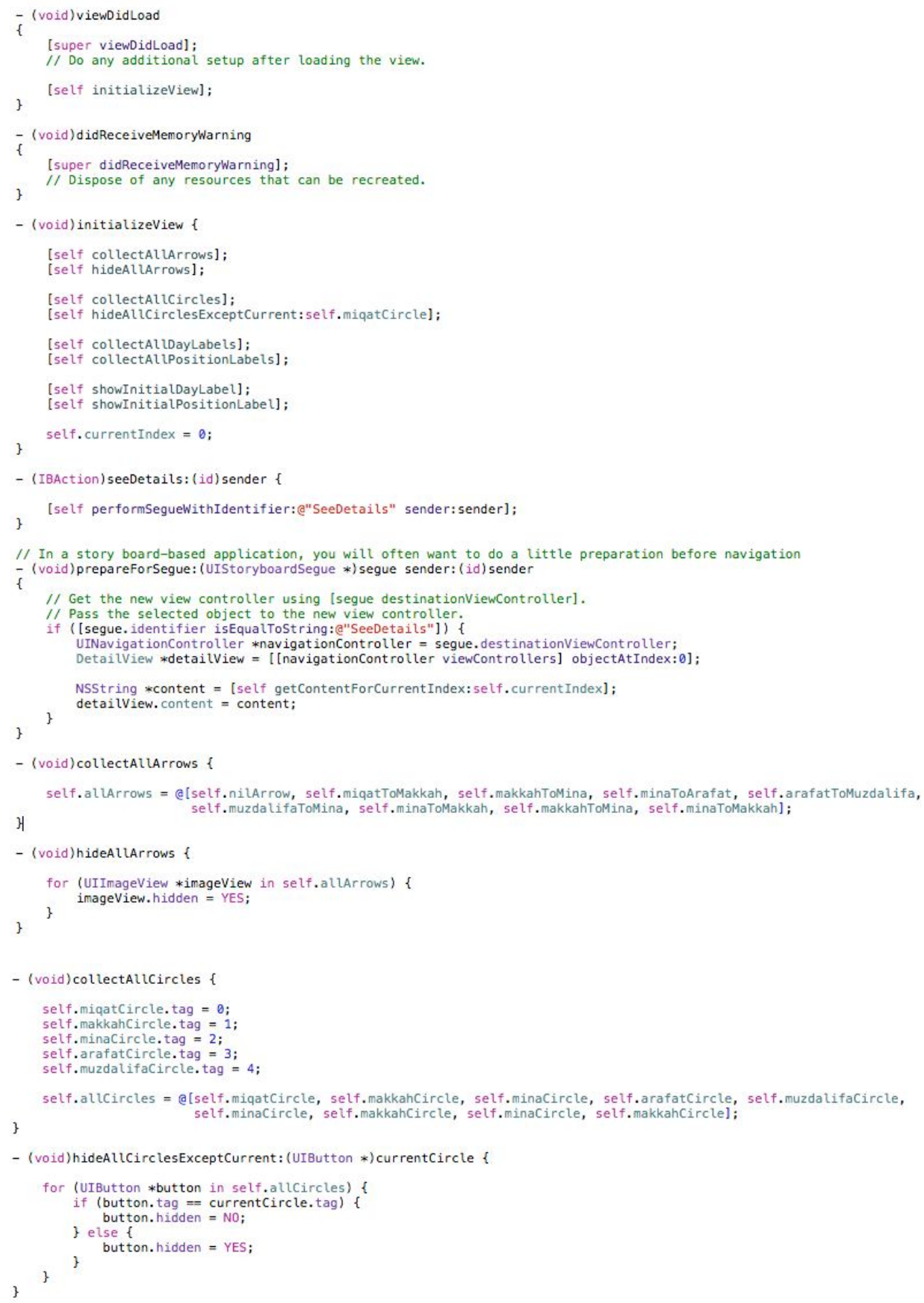


- (void) collectAllDayLabels \{

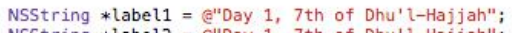

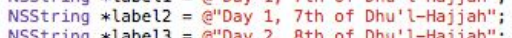

NSString *label $3=$ e "Day 2, 8th of Dhu'l-Hajjah";

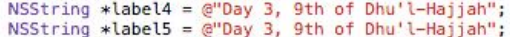

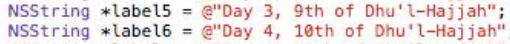

NSString *label6 $=$ @"Day 4, 10th of Dhu'l-Haj jah";
NSString *label7 $=$ @"Day 4, 10th of Dhu'l-Hajjah";

NSString *label $=$ G"Day 5,11 th of Dhu'l-Haj jah";

self.allDayLabels = @[label1, label2, label3, label4, label5, label6, label7, label8, label9];

- (void)collectallPositionLabels \{

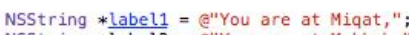

NSString $*$ label2 $=$ e"You are at Makkah,"

NSString $*$ label $3=e^{\text {"You }}$ are at Mina,";

NSString *labet $=$ e You are at Arafat,";

NSString $*$ label5 $=\mathfrak{e}^{\text {"You }}$ are at Muzdalifah,

NSString * tabet6 = e You are at Mina, ; "

NSString *labelo = e"You are at Mina,";"

NSString $*$ label9 $=$ G"You are at Makkah"

self.altPositionLabels = @[label1, label2, label3, label4, label5, label6, label7, label8, label9];

- (IBAction) resetMap: (id) sender \{

\}

[self initializeView];

- (IBAction) goToNextStop: (id) sender \{

if (currentIndex $>7)\{$
[self displayAlert];

[self showNextArrow];

[self shownextCircle];

[self showNextPositionLabel];

\}

self. currentIndex++;

- (IBAction)goToPreviousStop: (id) senderf

if (currentIndex $=0$ ) \{ return; \}

[self hideCurrentArrow];

[self showPreviouscircle];

[self showPreviousdayLabel];

[self showPreviousPositionLabel];

\}

self.currentIndex--;

- (void) showNextArrow \{

UIImageView *nextArrow $=$ self. allArrows [self. currentIndex+1]

- (void)hideCurrentarrow 1

UIImageView $*$ currentArrow $=$ self. atLArrows [self. currentIndex];

- (void)showNextCircle \{

UIButton $*$ nextCircle $=$ self. allcircles [self. currentIndex+1];

nextCircle.hidden $=$ NO;

[self hideCurrentCircle];

- (void)showP reviousCircle \{

UIButton $*$ previousCircle $=$ self.altcircles [self.currentIndex-1]; previousCircle , hidden $=$ NO

[self hideCurrentCircle]:

- (void)hideCurrentCircle \{

UIButton $*$ currentCircle $=$ self.allCircles [self.currentIndex]

\} currentCircle. hidden $=$ YES 


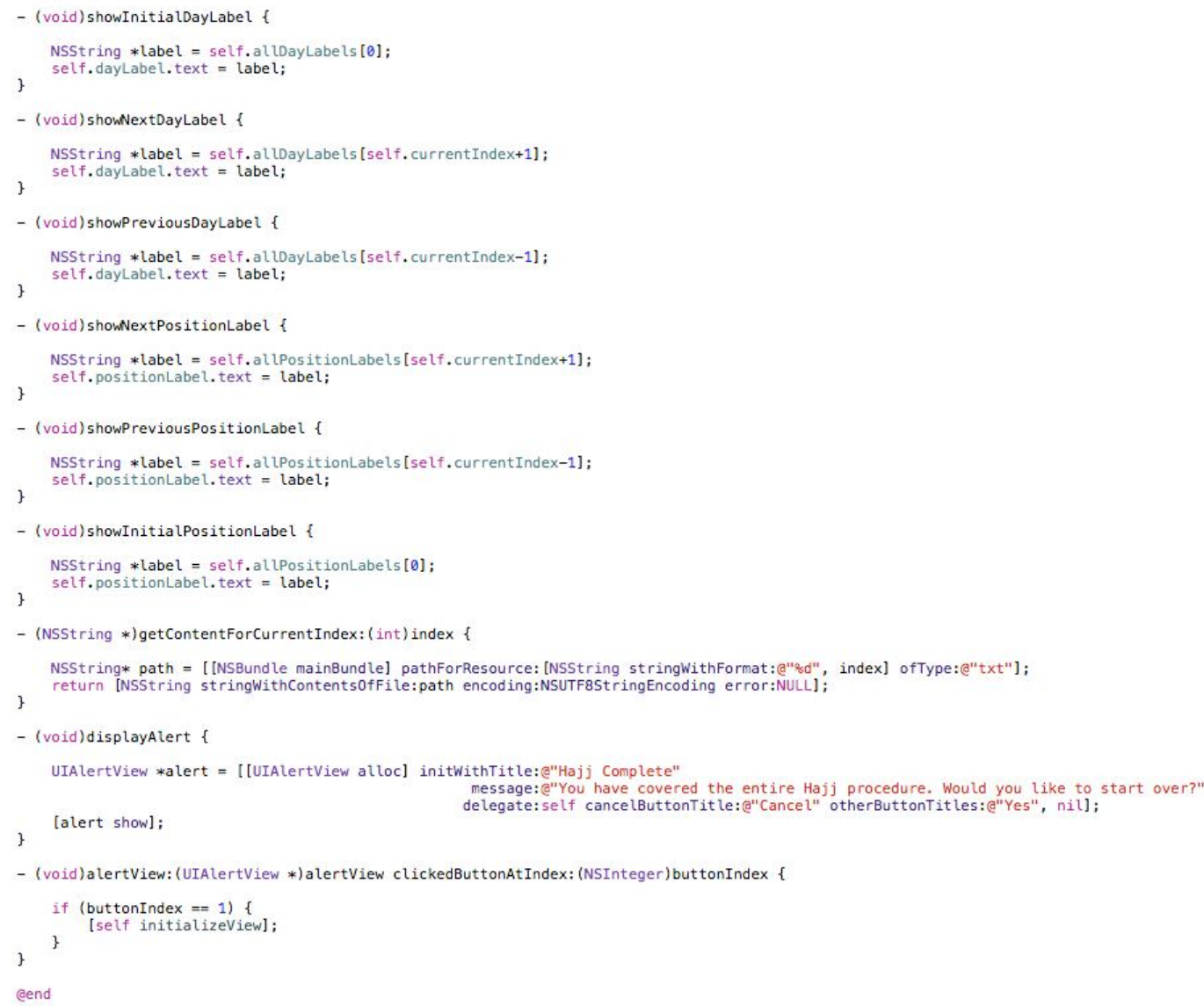

Fig. b2: Interactive Map Code. 


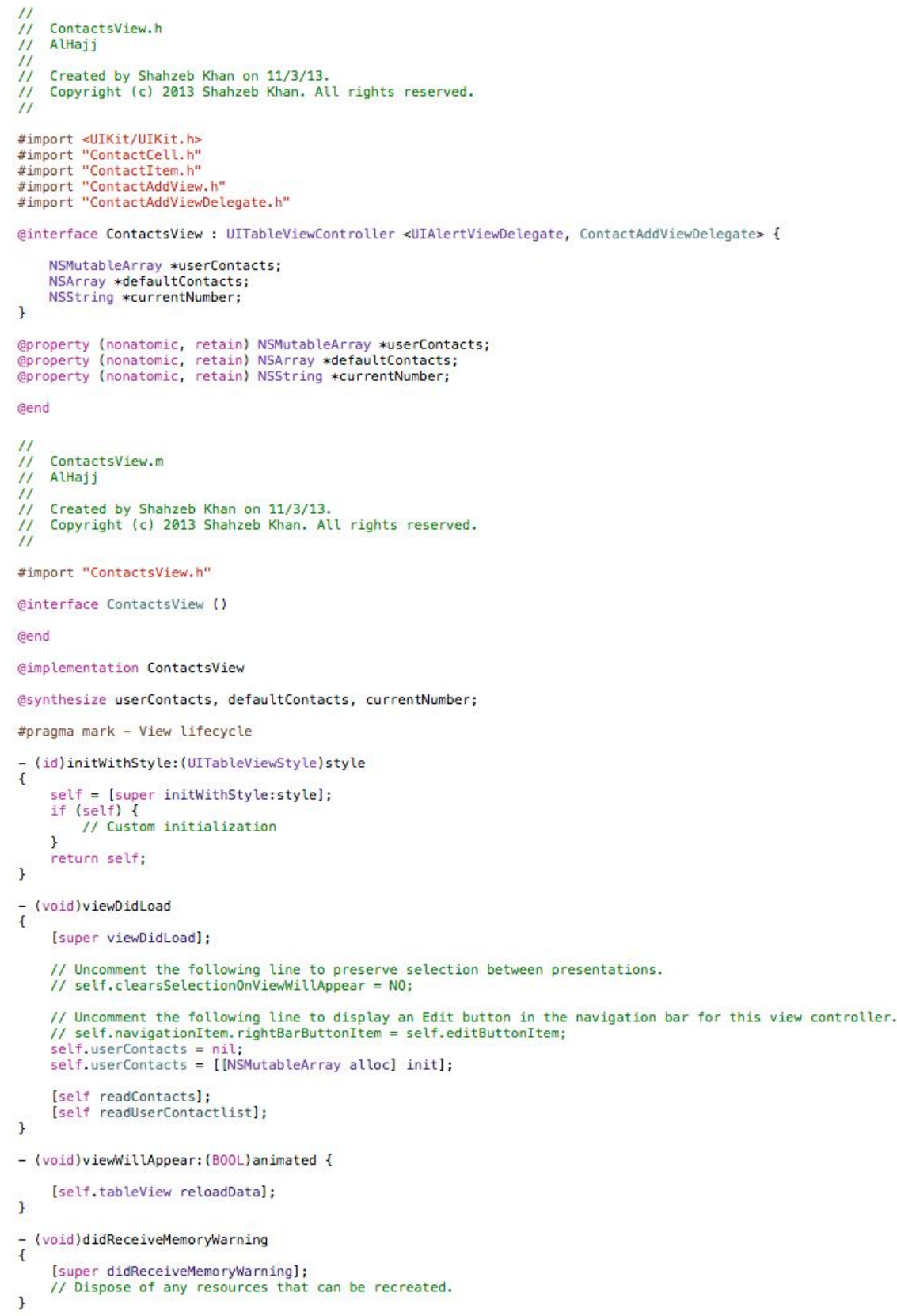




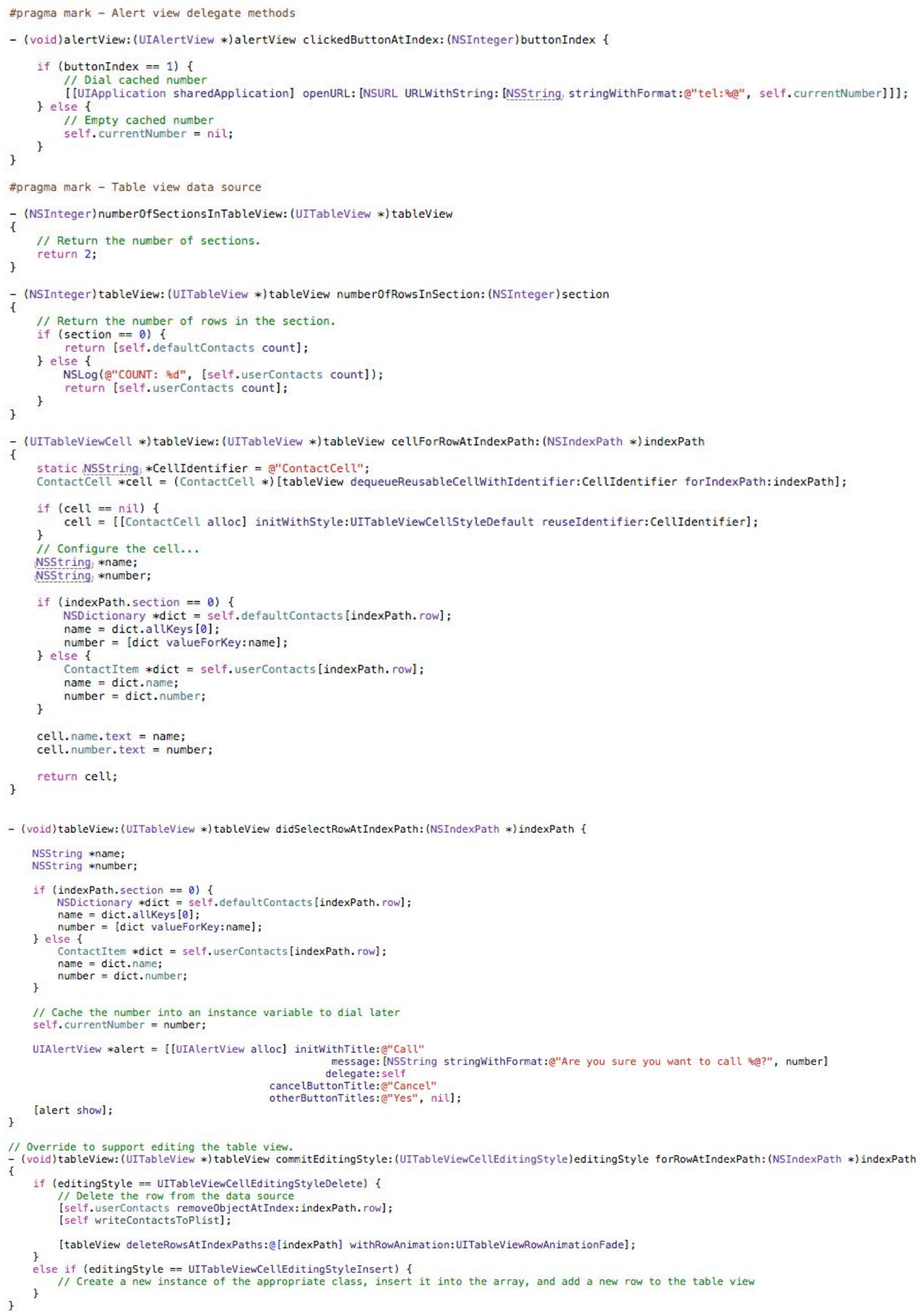




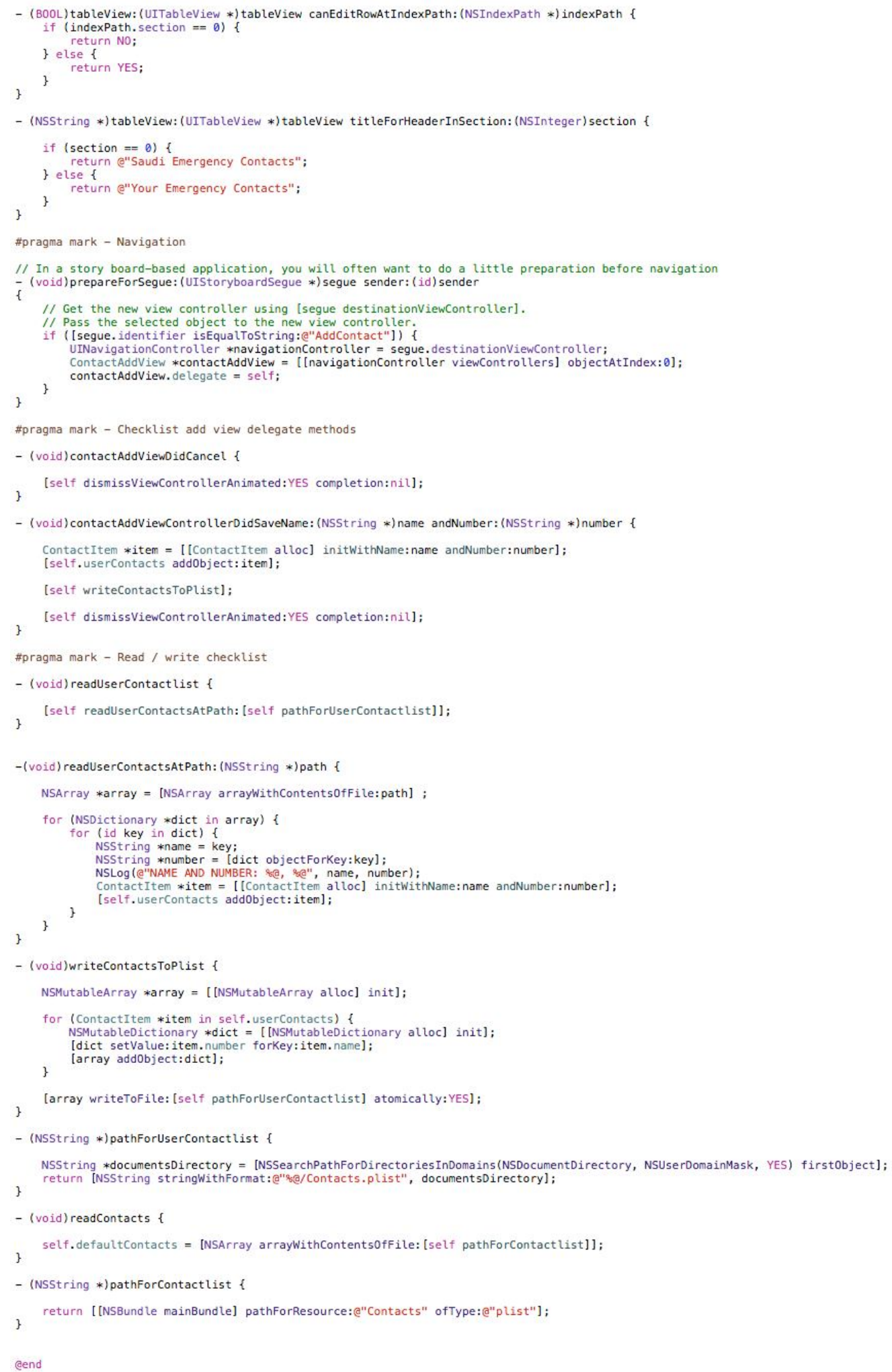

Fig. b3: Interactive Contact List Default. 


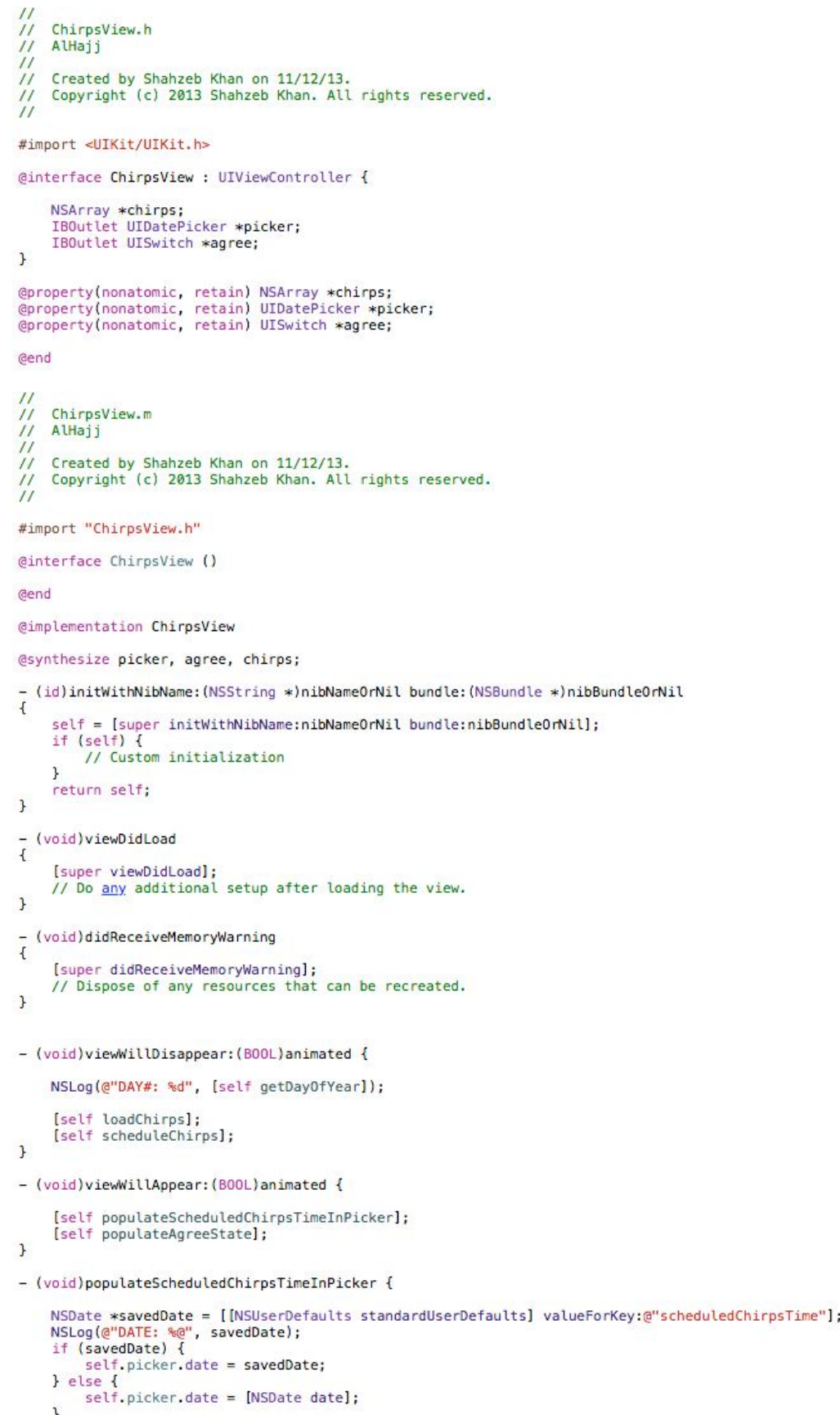




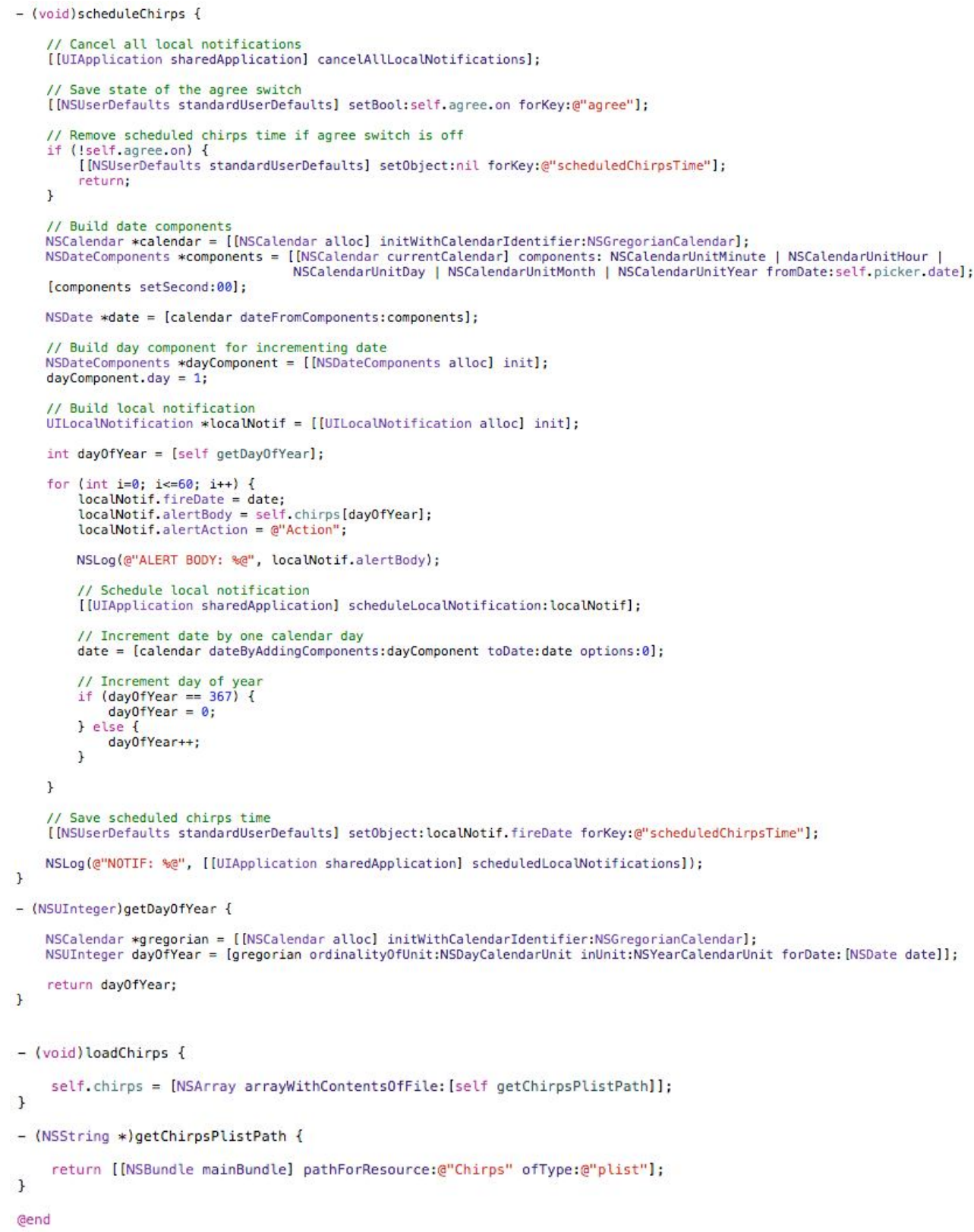

Fig. b4: Motivational Messages Code. 